\title{
How many doctors should Sri Lanka have?
}

\author{
N R de Silva ${ }^{1,2}$, K K Y W Perera ${ }^{1}$, R S Gunatunge ${ }^{1,3}$ and D A Tantrigoda ${ }^{1,4}$ \\ (Index words: physicians, medical workforce)
}

\section{Introduction}

Preparing a workforce that can attain the health objectives of a country is one of the formidable challenges faced by a health system [1]. Such a workforce must have reasonable balance in terms of numbers, diversity and competencies. Achieving this requires a thorough knowledge of the driving forces and challenges that shape health and education systems as well as labour markets. This knowledge can be used to guide policies and actions related to training and recruitment.

Understanding the dynamics of any workforce requires focus on when people enter, the period of their lives when they are part of the workforce, and the point at which they exit from it. This paper is an effort to understand the dynamics in relation to just one category of the health workforce in Sri Lanka: MBBS qualified doctors who are generally referred to as 'physicians' in the health workforce literature. Other categories of medical practitioners, such as Assistant and Registered Medical Practitioners, and non-Western medical practitioners, are not considered here.

\section{Entry into the workforce}

There are two categories of medical graduates who enter the workforce in Sri Lanka: graduates of local medical faculties, and foreign qualified medical graduates. All medical practitioners must obtain full registration with the Sri Lanka Medical Council (SLMC) before they are legally entitled to engage in professional practice. The SLMC grants full registration to local graduates on satisfactory completion of a year's internship, which usually commences 3-12 months after graduation. Registration is granted to foreign qualified graduates after they have passed all segments of the Examination for Registration to Practice Medicine (ERPM) and completed a year's internship.

During the period 2000-2006, the average annual output from the local medical faculties was 934 graduates, and average registration of foreign qualified medical graduates was 127 (table 1). Thus the average annual number of medical graduates (local and foreign qualified) eligible for provisional registration and internship during this period was 1061. But the annual average new full registrations with the SLMC during the same period was only 932 (table 1). This deficit can be attributed to a lag period of about 2 years between graduation and full SLMC registration, especially among foreign qualified graduates, combined with a slow increase in graduate output.

\section{Exit from the workforce}

The SLMC requires its members to renew their registrations once in 5 years; only those who do so are counted as 'active registrations'. The number of active full registrations increased by only an annual average of 885 during the period 2001-2007 (table 1), compared with 932 new annual average registrations during the period 20002006. This annual average deficit of about 50 doctors (about $5 \%$ of new registrations) probably results from the exit of doctors from active SLMC registration due to death, retirement from active work and overseas migration.

\section{Employment sector}

Medical graduates may work primarily in one of four different employment sectors after completing internship and obtaining full SLMC registration: (1) Ministry of Health, (2) university sector, (3) private sector, (4) overseas.

The Health Ministry reports annually on the number of its employees, but its count of medical officers includes interns who have not yet obtained full registration. Comparison of the number of SLMC registrations with the number of medical officers in position in the Health Ministry (with discount for interns) indicates, that on average, about $70 \%$ of those with active full registration with the SLMC are employed by the Ministry (table 1). As of 30 June 2007, the total academic staff in the 8 medical faculties in Sri Lanka was 612 [2]. If it is assumed that about $10 \%$ of this number are non-medical graduates, that would indicate that about $550(3 \%)$ of the 15977 active SLMC registrants are employed in the university sector. This means that $27 \%$ of those with active SLMC registration are either employed entirely in the private sector, or are overseas. In a recent (2006) previous attempt to estimate distribution of the medical workforce in the island [3], it was suggested that about $80 \%$ of the country's

\footnotetext{
${ }^{1}$ Policy and Strategy Development Unit, Ministry of Higher Education, ${ }^{2}$ Faculty of Medicine, University of Kelaniya, ${ }^{3}$ Faculty of Management Studies, University of Sri Jayewardenepura, and ${ }^{4}$ Faculty of Applied Sciences, University of Sri Jayewardenepura, Sri Lanka.

Correspondence: NRdeS, e-mail: <nrdes@sltnet.lk>. Competing interests: all authors were supported by the World Bank funded IRQUE project of the Ministry of Higher Education.
} 


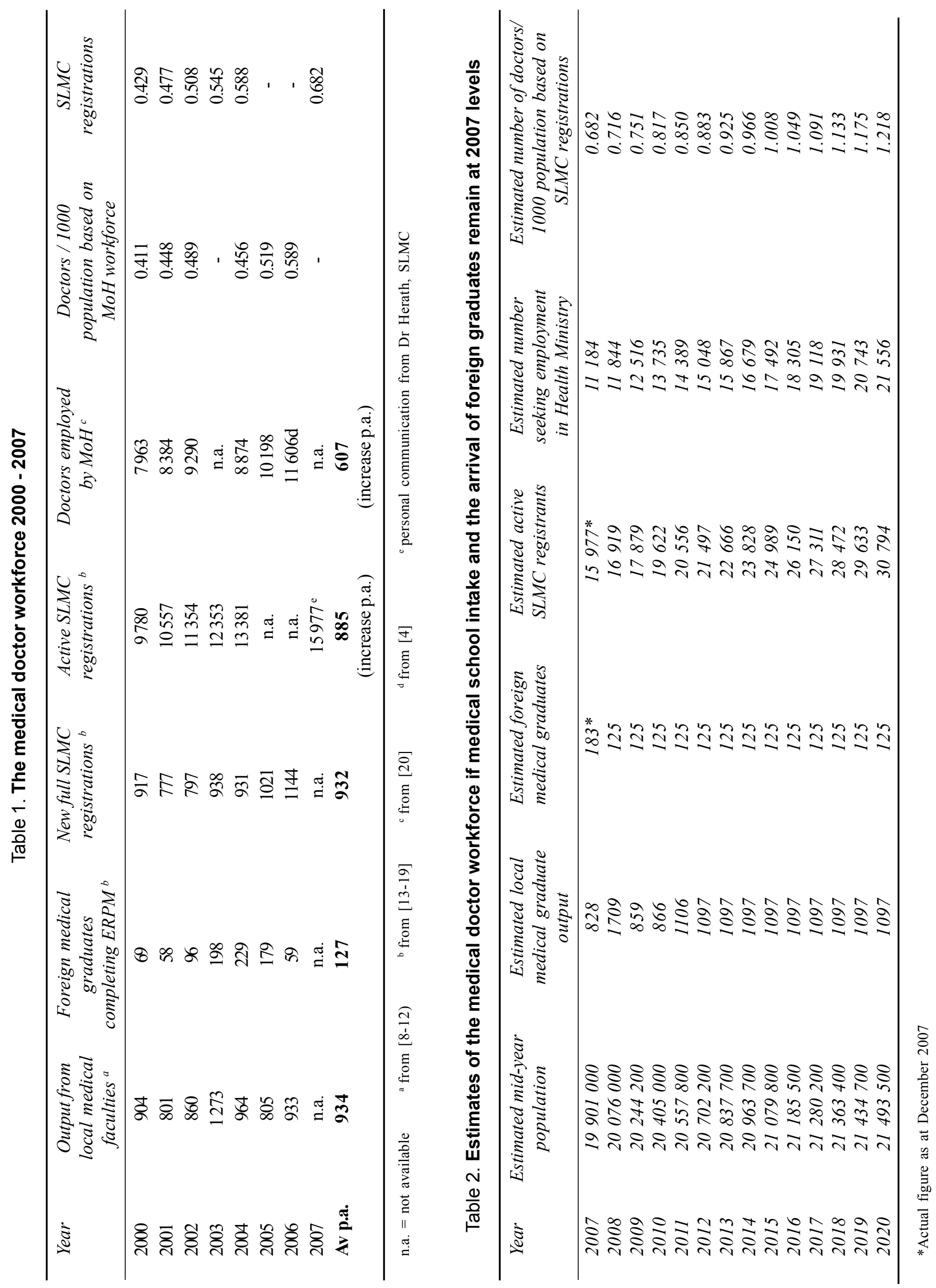


Figure 1. Dynamics of the medical doctor workforce in Sri Lanka.

Estimates of the medical workforce by 2020

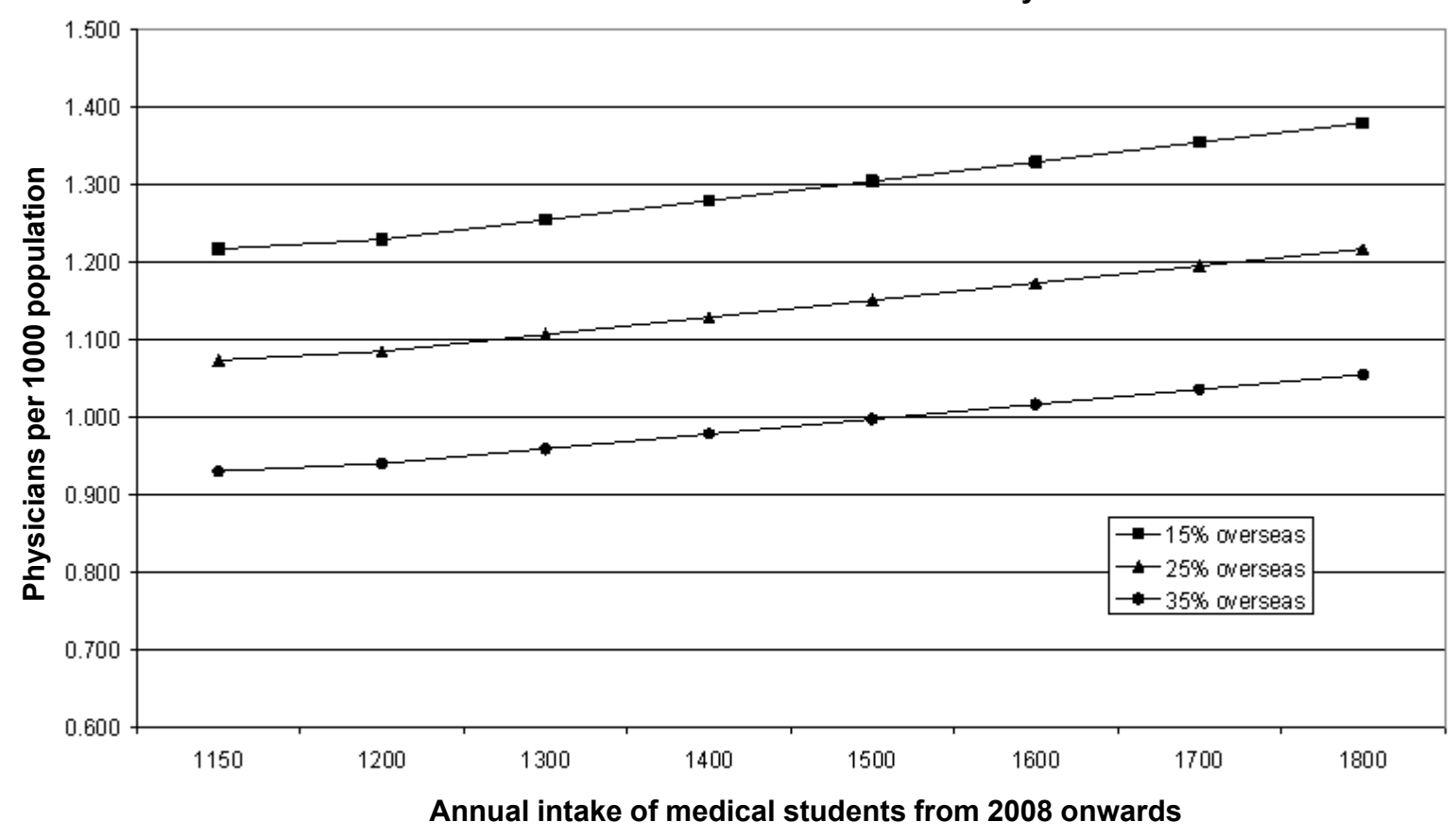

Figure 2. Alternative avenues for growth in the medical doctor workforce. 
medical workforce was employed by the Ministry of Health and $3 \%$ by the universities, while the rest $(17 \%)$ were employed in the private sector as general practitioners (554 doctors) and in private hospitals (1200 doctors). However, according to data now available on the Health Ministry website [4], a national census of health manpower conducted at the end of 2006 showed that the Ministry actually employed about 3000 more medical graduates than was assumed in the 2006 estimate. If the number in the public sector is adjusted assuming that the estimate of 1750 doctors in the private sector is correct, the proportion of the medical workforce in the private sector in 2006 was about $12 \%$ and not $17 \%$.

Thus it would seem reasonable to assume that about $70 \%$ of Sri Lanka's medical doctor workforce (as indicated by those with active full registration with the SLMC) is employed in the Health Ministry, about 3\% in the universities, about $12 \%$ in the private sector, and the remaining $15 \%$ are overseas.

On the assumption that only $85 \%$ of those with active SLMC registrations are practicing in Sri Lanka, the number of doctors per 1000 population can be calculated for each year using estimates from the Department of Demography, University of Colombo (Indralal de Silva, personal communication). On this basis, the number of doctors per 1000 population has increased from 0.43 in 2000 to 0.68 in 2007 (table 1).

The annual average increase in medical officers employed by the Ministry of Health during the period 2000-2006 has been about 600 . This is a net increase, which takes into account new recruits from among local and foreign qualified graduates, as well as exit from the Ministry to the university or private sectors, overseas migration, retirement or death. This number suggests that only about $65 \%(607 / 932)$ of new full SLMC registrations during that period has contributed towards increasing the Health Ministry workforce. The rest comprises doctors replacing medical officers who retire from the Ministry, doctors entering the university sector, doctors entering the private sector in Sri Lanka, and doctors seeking employment overseas (see figure 1).

\section{Predicting the future}

The expected graduate output for the period 20072020 can be calculated assuming that $95 \%$ of the medical school intake in a given year graduate 5 years later, together with the addition of a certain number of foreign qualified medical graduates. The medical workforce can be estimated for each year during this period, on the assumptions that the annual increment in active SLMC registrations is about $95 \%$ of the total graduate output two years previously; that $70 \%$ of active SLMC registrants would seek employment in the Ministry of Health; and that $15 \%$ go overseas and are not part of the active workforce in the country. It is also possible to set these factors at varying levels and explore different outcomes.
For example, if local medical schools intake remains static at the 2007 level of 1150 , and the foreign qualified medical graduates entering the workforce also remains static at the current average of 125 per annum, active SLMC registrations will reach about 30800 by 2020 and we will have 1.2 active physicians / 1000 population (table 2), provided that overseas migration also remains at $15 \%$.

At present the medical schools intake is based only on how many students can be accommodated within the existing infrastructure, but it is also possible to set a target in terms of how many doctors Sri Lanka should have by a given year, estimate the other variables, and then work towards achieving that target by adjusting the intake. This brings us to the question posed in the title of this paper: how many doctors should Sri Lanka have?

\section{Setting a target}

Despite its developing country status, Sri Lanka has health indices which resemble those of more affluent countries. For example, in 2004 life expectancy at birth was 71 years in Sri Lanka, compared with 62 in India and Pakistan, 78 in the USA and 79 in the UK. The under-5 mortality rate was 14 for Sri Lanka, compared with 85 in India, 101 in Pakistan, and between 5 and 8 in the UK, the USA, and Australia [1].

Sri Lanka's medical workforce statistics are very different from those of more affluent countries. In 2004, the UK, USA and Australia had 2.3-2.56 doctors / 1000 population, while India and Pakistan had 0.6 and 0.74 doctors /1000 population. Malaysia and Thailand had 0.70 and 0.37 respectively in 2000, and Indonesia had 0.13 in 2003 [1]. Sri Lanka is listed in the same database as having 0.55 physicians / 1000 population in 2004 , which is more than the rate based on the Health Ministry workforce (0.456) and closer to our estimate based on SLMC registrations $(0.588)$ for the same year. Whatever the actual value, comparison with other countries suggests that Sri Lanka should aim to increase its medical doctor workforce. When national figures are broken down further to show regional distribution of doctors, this need becomes even more evident [3].

\section{Medical graduate unemployment?}

In May 2008 the Presidential Secretariat, the Ministry of Healthcare and Nutrition, the Postgraduate Institute of Medicine and the Government Medical Officers Association launched a Foreign Placement Coordinating Centre for Medical Officers. Among its other functions, this centre will 'arrange foreign placements for specialists and non-specialist medical officers' in order to deal with 'the issue of unemployment of doctors after 2010' [5]. Unemployment has so far not been a problem for medical graduates in Sri Lanka because the Ministry of Health has offered employment to all of them. So why has it been assumed that it will be a problem after 2010 ? 
In 2003 the Management Development and Planning Unit of the Ministry of Healthcare and Nutrition prepared cadre projections up to 2010. These provide for the employment by 2010 of 14286 medical officers, inclusive of administrative grades, special grades, grade medical officers and interns (Dr S. Samarage, personal communication). Based on the comparison of these projections with estimates of medical graduate output, the Ministry declared that from 2010 onwards it will not be able to offer employment to all medical graduates. This statement has been interpreted as a looming spectre of unemployment, and it is now suggested that Sri Lanka should deal with this 'problem' by exporting its medical graduates.

The estimates presented here, using the assumptions set out above, suggest that cadre saturation will occur around 2011. Whether it occurs in 2010 or 2011 , does cadre saturation mean that Sri Lanka would have by then met its need for doctors with inevitable unemployment for Sri Lankan medical graduates? Will Sri Lanka have so many doctors by 2010 that the State should support export of their skilled labour?

If the government is to maintain absorbing $70 \%$ of the medical graduate output even after 2010, the medical officer cadre in the Health Ministry will have to increase by about 650 each year, to reach 17500 by 2015 and about 21500 by 2020 (table 2). Given the current state of the economy, this does not appear likely. It could be argued that provided it can meet the health needs of those who cannot afford private health care, the State has no obligation to guarantee employment to all medical graduates. In the UK, where there is growing evidence that several thousand UK medical graduates may not be able to pursue a career in medicine because they are unable to secure training places (filled by overseas graduates who compete with local graduates for these places), it has been argued that 'the purpose of the National Health Service is to deliver patient care that is compassionate and efficient and not to guarantee the employment of medical graduates' [6].

What about employment in the private sector in Sri Lanka? Currently, the private sector employs about 10$15 \%$ of the medical doctor workforce. This is at variance with the estimate that about $55 \%$ of the total expenditure on health in this country is private [1]. Given the private expenditure on health, it is reasonable to assume that the private sector will be able to absorb a much larger proportion of medical graduates than it does at present. It has been suggested that with better preparation and training, and some incentives from the State, many more doctors would be ready to opt for full time private practice as family physicians [7]. Already the MBBS courses of the Universities of Kelaniya and Sri Jayewardenepura include formal training in family medicine. Private hospitals have also increased in size and number over the last decade, and are likely to continue to do so. Growth in private hospital bed strength would be almost certainly accompanied by an increase in the number of doctors employed.

\section{Alternative scenarios}

Even if the private health sector grows significantly, if there is no guarantee of State sector employment, the proportion of medical graduates seeking employment overseas is bound to rise above the current level of $15 \%$. If it increases to $25 \%$, and the medical school intake is kept at current levels, Sri Lanka will have only 1.1 physicians / 1000 population by 2020 , and if overseas migration increases to $35 \%$, the rate will be 0.9 physicians / 1000 population (figure 2). If migration rises to $25 \%$, medical school intake needs to be raised to 1800 annually to reach the physicians per 1000 population rate that we would have achieved if migration did not increase (ie. 1.2 physicians / 1000 population).

The WHO has identified a threshold in workforce density below which high coverage of essential interventions, including those necessary to meet the health-related millennium development goals, is very unlikely. Based on these estimates, it has listed 57 countries with critical shortages equivalent to a global deficit of 2.4 million doctors, nurses and midwives [1]. Sri Lanka is not one of these 57 countries. It may be argued that Sri Lanka has achieved good health indices despite having a comparatively small medical doctor workforce, and that attempts to markedly accelerate the local production of medical graduates will only result in deterioration in standards of training, and consequently, the quality of our medical graduates. This concern needs to be offset against the possibility that overseas migration could increase in the near future.

The whole country stands to benefit if the Ministries of Health and Higher Education coordinate their policies. If it is decided that the country should have, say, 1.2 doctors / 1000 population by 2020 , it is possible to estimate the medical student intake required in the immediate future to achieve this target. If State funded universities are unable to find the resources to support this number of students, the Higher Education Ministry will need to take a long, hard look at alternative measures.

\section{Acknowledgements}

We thank the Registrar and Assistant Registrar of the SLMC for providing data on SLMC registrations, and Dr S Samarage, DDG (Planning), and Dr Wijekoon at the MDPU, Ministry of Healthcare and Nutrition, for helpful discussions.

\section{References}

1. World Health Organization. The World Health Report 2006: working together for health. Geneva: World Health Organization, 2006. 
2. IRQUE Project. Statistics of academic staff and students in public universities in Sri Lanka-2007. Colombo, Improving Relevance and Quality of Undergraduate Education Project, Ministry of Higher Education, 2007.

3. Mendis L. Human resources for health, situation analysis with regard to doctors and specialists as at April 2006. In: Mendis L, Goonaratna C, Abeygunasekera A, Abeykoon P (eds). Balancing the demand and supply of doctors in Sri Lanka. Colombo: proceedings of the WHO / SLMA Symposium held on 15 May 2006.

4. National census of health manpower updated on 31.12. 2006. Accessed at http://www.health.gov.lk/Summary.pdf on 18 May 2008.

5. Padeniya A, Wickremasinghe W (editors). Health sector contribution to knowledge economy. Colombo: Presidential Secretariat / Ministry of Healthcare and Nutrition / Postgraduate Institute of Medicine / Government Medical Officers Association, 2008.

6. Maynard A. Does it matter that medical graduates don't get jobs as doctors? No. British Medical Journal 2008; 336: 991.

7. Ferdinand WA. Private sector perspective. In: Mendis L, Goonaratna C, Abeygunasekera A, Abeykoon P (eds). Balancing the demand and supply of doctors in Sri Lanka. Colombo: Proceedings of the WHO / SLMA Symposium held on 15 May 2006.

8. UGC. Sri Lanka University Statistics 2001. Colombo: University Grants Commission, 2001.
9. UGC. Sri Lanka University Statistics 2002. Colombo: University Grants Commission, 2002.

10. UGC. Sri Lanka University Statistics 2004. Colombo: University Grants Commission, 2004.

11. UGC. Sri Lanka University Statistics 2005. Colombo: University Grants Commission, 2005.

12. UGC. Sri Lanka University Statistics 2006. Colombo: University Grants Commission, 2006.

13. SLMC Annual Report 2000. Colombo: Sri Lanka Medical Council, 2000.

14. SLMC Annual Report 2001. Colombo: Sri Lanka Medical Council, 2001.

15. SLMC Annual Report 2002. Colombo: Sri Lanka Medical Council, 2002.

16. SLMC Annual Report 2003. Colombo: Sri Lanka Medical Council, 2003.

17. SLMC Annual Report 2004. Colombo: Sri Lanka Medical Council, 2004.

18. SLMC Annual Report 2005. Colombo: Sri Lanka Medical Council, 2005.

19. SLMC Annual Report 2006. Colombo: Sri Lanka Medical Council, 2006.

20. Ministry of Healthcare and Nutrition. Annual Health Statistics 2005. Accessed at http://203.94.76.60/AHB2005/ AnnualHealth\%20Bulletin2005.htm on 22 May 2008.

\section{The Inquest}

I took my oath I would inquire, Without affection, hate, or wrath,

Into the death of Ada Wright

So help me God! I took that oath

When I went out to see the corpse, The four months' babe that died so young,

I judged it was seven pounds in weight And little more than one foot long

One eye, that had a yellow lid,

Was shut - so was the mouth, that smiled;

The left eye open, shining bright -

It seemed a knowing little child

William Henry Davies, English poet. (1871 - 1940) 